\title{
PETICIONES EN LA CONVERSACIÓN EN LENGUA CHINA: METODOLOGÍA PARA LA COMPARACIÓN INTERLINGÜÍSTICA*
}

\author{
REQUEST IN CHINESE CONVERSATION: METHODOLOGY \\ FOR INTERLINGUISTIC COMPARISON
}

\author{
María Querol Bataller \\ Universidad Católica de Valencia San Vicente Mártir \\ maria.querol@ucv.es
}

Enviado: 01/12/2017

Aceptado: 05/10/2018

\section{Resumen}

El fin del presente trabajo es contribuir al desarrollo de los estudios de pragmática intercultural, especialmente en lo que a la lengua china y española se refiere. Con este fin se analiza, desde la perspectiva hispanohablante, la realización de un tipo de acto de habla, las peticiones, en el discurso conversacional oral en lengua china obtenido a partir de la transcripción de varios capítulos de la serie 勿匀 那年 : 好久不见 (Back In Time: Long Time No See). Los resultados del análisis propuesto, así como la referencia a los obtenidos en otras investigaciones análogas, muestran, además de una aproximación al habla real de los hablantes chinos, algunas claves metodológicas que permitirían la interpretación de los resultados en

\begin{abstract}
The aim of this paper is contribute to the development of intercultural pragmatic research, especially as far as the Chinese and Spanish language are concerned. In order to do this, it has been analyzed, from Spanish speaking point of view, one kind of speech act, request, in Chinese conversation. The Chinese serie 匀 匀那年 : 好久不见 (Back In Time: Long Time No See) was used to take the samples. The results show some clues about the real speech of Chinese speakers, and not only about their linguistic awareness. Besides, the paper also shows some methodological keys that would allow the interpretation of the results in specific researches, as well as the extrapolation and comparison of the conclusions.
\end{abstract}

\footnotetext{
* El presente trabajo ha sido posible gracias a la financiación recibida en el proyecto "La atenuación pragmática en el español hablado: su variación diafásica y diatópica” (Ministerio de Economía y Competitividad de España, ref. FFI2013-40905-P)
}

Para citar este artículo / To cite this article: Querol, María (2018). Peticiones en la conversación en lengua china: metodología para la comparación interlingüística. ELUA, 32: 263-289. doi: 10.14198/ ELUA2018.32.12

Enlace / Link: http://dx.doi.org/10.14198/ELUA2018.32.12 
investigaciones particulares, así como la extrapolación y comparación de las conclusiones.

PALABRAS CLAVE: chino, conversación, petición, atenuación, intensificación.
KEYWORDS: Chinese, conversation, request, attenuation, intensification.

\section{INTRODUCCIÓN}

Los estudios de pragmática intercultural, especialmente en lo que a las relaciones entre la cultura china y española se refiere, se encuentran todavía en una fase incipiente. Varios son los motivos que pueden explicar esta situación: en primer lugar, el hecho de que hasta el momento hayan sido las cuestiones que atañen al componente gramatical, léxico o fonológico, las que han recibido mayor atención por parte de los investigadores; en segundo lugar, la escasa difusión e intercambio académico existente entre las comunidades científicas china y española, que no contribuye a que los logros de una sean explotados y aplicados en la otra; y, en tercer lugar, la diversidad de metodologías y variables de análisis utilizadas en las investigaciones, lo que en múltiples ocasiones tampoco permite extrapolar y contrastar los resultados obtenidos. Por tanto, contribuir al desarrollo de los estudios de pragmática intercultural chino-español español-chino es uno de los objetivos de este trabajo; sin embargo, también lo es incrementar la productividad de los estudios particulares, de tal forma que, una vez realizados, sea posible establecer comparativas y contrastes.

Por otra parte, dado que la diferencia en el uso y realización de los actos de habla es una de las causas más importantes que subyacen a los malentendidos culturales, analizar, desde la perspectiva hispanohablante, la realización que de las peticiones hacen los hablantes chinos en un tipo de discurso concreto, la conversación, será un objetivo fundamental de este trabajo.

Dicho todo esto, los objetivos concretos de este trabajo son los siguientes:

a) contribuir al desarrollo de los estudios de pragmática intercultural chino-español, español-chino

b) analizar el acto de habla de petición en contextos conversacionales orales en lengua china $^{1}$

\section{2. 匀匀那年: 好久不见 (BACK IN TIME: LONG TIME NO SEE)}

En este trabajo se parte de una concepción etnolingüística de la cultura, según la cual esta «is a fuzzy set of basic assumptions and values, orientations to life, beliefs, policies, procedures and behavioural conventions that are shared by a group of people, and that influence each member's behaviour and each member's interpretations of the 'meaning' of other people's behaviour» (Spencer-Oatey, 2008: 4). Además, se considera aquí que los patrones culturales o la cosmovisión de una determinada comunidad se reflejan, en cierto modo, en sus producciones y manifestaciones culturales, entre las que evidentemente se

1 En este trabajo la palabra chino o lengua china se usa para denotar la variedad estándar de la lengua china, el putonghua (普通话). 
encuentra la lengua. En este sentido, Raymond R. Williams definía la cultura como «una creación individual y colectiva de significados, modos de sentir y de actuar, incardinada en un lenguaje -en un idioma- enmarcada en instituciones sociales concretas y condicionada por unas circunstancias materiales determinadas» (Coll, 1997: 36). Siendo así, para lograr los fines de este trabajo se escogió un producto cultural como son los episodios de una serie emitida en la televisión china con notable éxito y de contextualización nacional匀匈那年: 好久不见 (Back In Time: Long Time No See).

匀匀那年: 好久不见 (Back In Time: Long Time No See) es una serie de producción y emisión en la televisión china durante 2015, la 1. ${ }^{a}$ temporada, y 2016, la 2. ${ }^{a}$ temporada. La serie se contextualiza en el momento actual en la ciudad de Beijing cuando sus protagonistas, 5 jóvenes que estudiaron juntos en el instituto, se reencuentran unos años después.

El visionado de la serie permite detectar, en las acciones y en los usos lingüísticos y discursivos de los personajes, algunas singularidades, al menos desde el punto de vista hispanohablante, de la cultura china ${ }^{2}$. A modo de ejemplo, a continuación se indican algunos aspectos culturales que se consideran característicos, aunque no exclusivos, de la sociedad china y que se encuentran representados lingüísticamente en los capítulos VI y VII.

a) La ordenación jerárquica de la sociedad. En la sociedad china la utilización del nombre de pila queda restringida al ámbito más próximo e íntimo, y fuera de este se suele preferir el uso del apellido para identificar a las personas. Además, no es extraño que, especialmente en los ambientes más formales, se haga referencia al cargo o desempeño profesional. Por ello, es muy significativo que en la serie a todos los personajes que ocupan una posición de superioridad se les identifique con el cargo que ocupan: 科长 (Ke Zhang, 'jefe de departamento'), 广主任 (Kuang Zhuren, 'presidente Kuang'), 曾总 (Zeng zong 'director Zeng')... Por el contrario, 陈寻 (Chen Xun), uno de los protagonistas y que trabaja para 科 长 (Ke Zhang, 'jefe de departamento'), incluso es referido por este con el apelativo 小 (xiao, 'pequeño'), 小陈 (Xiao Chen, 'pequeño Chen'). Asimismo, es muy significativo el uso de términos de parentesco, por ejemplo 哥 ( $g$ e, 'hermano'), para referirse a amigos y compañeros. En este caso se constatan dos usos diferenciados, que se pueden observar en los siguientes ejemplos:

1) Zhao Ye quiere que su amigo, Qiao Ran, le cuente si tiene novia, y utiliza como estrategia persuasiva el apelativo 哥 ( $g e$, 'hermano') para referirse a este último (los hermanos se cuentan confidencias).
(1) 赵烨: 跟哥说说
'Zhao Ye: con un hermano habla habla
哥帮你保密
hermano te ayudaré a guardar el secreto'

2) Chen Xun pregunta por uno de sus compañeros de departamento y se refiere a él con el apelativo哥 ( $g e$, 'hermano'). Este uso refuerza el sentido de solidaridad grupal, ya que ambos son trabajadores y subordinados del jefe de departamento.

2 El hecho de que en el seno de un grupo social co-ocurran patrones, no niega la variación individual, diacrónica o diafásica (Placencia, 2010: 400-404). 
(2) 科长: 褚锐出事了

'Jefe de dep.: Rui Suo se metió en problemas'

陈寻: 锐哥他怎么了

'Chen Xun Hermano Suo ¿qué ha pasado?'

科长：嫖娼!

'Jefe: de dep. ¡Prostitución!'

b) La referencia a uno mismo con la máxima humildad, reserva y modestia (Gao y Ting-Toomey, 1998: 35-52). Se podría observar esta actitud, por ejemplo, en las respuestas a cumplidos (3). Un uso lingüístico similar a este no es propio y exclusivo de los hablantes chinos, pues se constata en muchas otras lenguas y sociedades, si bien será la frecuencia de uso, entre otros aspectos, lo que determinará su singularidad.

(3) 陈寻意不错啊

'Chen Xun: Hoy el negocio no va mal $\mathrm{PM}^{1}$ ',

还 凑合吧, 来来

'Cocinero: No demasiado mal $\mathrm{PM}^{2}$, vamos vamos'

c) El estilo de comunicación no asertivo e implícito, especialmente cuando el contenido de la comunicación conlleva transmitir información embarazosa o contraria a los intereses del oyente (Du, 1995; Ma, 1996; Gao y Ting-Toomey, 1998: 61-66). La realización de peticiones vinculadas a situaciones comprometidas, como es la violación de una de las protagonistas, 方茴 (Fang Hui), podría constatar dicha afirmación (4); sin embargo, para determinar empíricamente la tendencia hacia el estilo de comunicación no asertivo e implícito de los hablantes chinos sería necesario, por ejemplo, analizar, cuantitativa y cualitativamente, los actos directivos, tarea que aborda este trabajo, o los mecanismos evidenciales en sus manifestaciones lingüísticas (5) (6).

(4) 赵烨: 过去的事说重要也重要

说不重要也就是吹口气就没了的事

'Qiao Ran: Sobre el asunto del pasado, digo que lo que es importante es importante lo que no es importante puede desaparecer con un solo suspiro'

(5) 嘉茉: 其实我们早就该搬走了本 来你家也不大，我们还把你卧室给点着了

'Jia Mo: Verdaderamente tendríamos que habernos ido hace tiempo parece que tu casa no es muy grande, y encima nos hemos quedado tu dormitorio'

3 啊 (a) es una partícula modal, y como tal carece de significado léxico, pero pragmáticamente se usa con valor intensificador de la fuerza ilocutiva. Un equivalente en español podría ser la partícula ¿eh?, especialmente, los dos primeros usos que se describen en Briz, Pons y Portolés (2008):

1) "Apela al oyente solicitando de manera reforzada que confirme, ratifique o acepte lo dicho o lo que el hablante le pide, con frecuencia un cambio de actitud, de forma expresa o sobreentendida."

2) "Reafirma lo que el propio hablante dice a la vez que parece llamar la atención del oyente para que se alíe con él y con lo que está diciendo."

4 吧 (ba) es una partícula modal, y como tal carece de significado léxico, pero pragmáticamente se usa con valor atenuador de la fuerza ilocutiva. En actos aseverativos, por tanto, reduce el compromiso del hablante con lo dicho. 


\section{(6) 方茴: 我觉得不错 \\ 我支持你 \\ 'Fang Hui: Yo pienso que no está mal \\ yo te apoyaré'}

En esta pequeña introducción se ha intentado mostrar cómo es posible corroborar, o desacreditar, empíricamente algunos de los supuestos y principios que se atribuyen a los hábitos culturales y comunicativos de los hablantes de determinada comunidad lingüística. Así, comprobar si se trata de supuestos reales o estereotipados se deriva de vincular estos a realizaciones lingüísticas concretas y su posterior análisis en muestras de habla reales. Este trabajo contribuye a conseguir dicho objetivo describiendo y valorando el uso que de un tipo de acto de habla, las peticiones, realizan los hablantes chinos en contextos conversacionales orales.

\section{METODOLOGÍA}

Como ya se ha mencionado, este trabajo se centrará en el análisis de un tipo de producción lingüística concreta: el acto de habla de la petición en la conversación oral en lengua china. Para ello se analizó la muestra de habla formada por la transcripción de dos capítulos (VI y VII), cada uno de los cuales tiene una duración de $40 \mathrm{~min}$, de la $1^{\text {a }}$ temporada de la serie 匀匀那年: 好久不见 (Back In Time: Long Time No See).

La muestra objeto de análisis tiene carácter conversacional y oral, pero no es espontánea, pues tanto las acciones como los parlamentos han sido planificados; no obstante, la coetaneidad y éxito de la serie permiten pensar que estos son imitados con bastante similitud, o que, al menos, responden a las expectativas del público chino sobre cómo se comporta y se habla en la actualidad. Además, hasta el momento no hay a disposición pública, o al menos no tenemos conocimiento, corpus conversacionales, orales y espontáneos para el chino análogos a los existentes para el español (Corpus Val.Es.Co. 2.0.).

Una vez transcritos los diálogos se seleccionaron las muestras de habla que, por su contenido e intención, pudieran identificarse como petición. Con el fin de que los resultados obtenidos permitan la comparación interlingüística, utilizamos como variables de análisis del acto de habla las propuestas realizadas por grupos de investigación ya consolidados y de referencia. Así pues, en este trabajo se analiza la realización de peticiones y disculpas atendiendo a los siguientes criterios:

a) Estrategias de petición utilizadas en el núcleo del acto de habla (Blum-Kulka, House y Kasper, 1989)

b) Nómina y tipología de recursos atenuadores (Cestero y Albelda, 2012; Briz y Albelda, 2013).

c) Nómina y tipología de recursos intensificadores (Albelda, 2007; Briz, 2017)

d) Actos de apoyo: número y posición (Blum-Kulka et alii, 1989)

e) Nómina y tipología de alertadores (Blum-Kulka et alii, 1989)

En los últimos años el estudio de la atenuación y la intensificación lingüística se ha convertido en un tema nuclear en el Análisis del Discurso y la Pragmática, lo que ha permitido 
notables avances en lo que a las bases teóricas y metodológicas para su definición, caracterización y análisis se refiere. Es por ello que, atendiendo a esta realidad, en la atenuación e intensificación no se contempla la propuesta de Blum-Kulka et alii (1989). Por otra parte, es necesario considerar que, aunque los patrones de análisis utilizados corresponden a aportaciones de notable reconocimiento y difusión en el ámbito científico y académico, no fueron ideados para una investigación como la que aquí se presenta, por lo que ha sido necesario realizar algunas adaptaciones. Quizá la más evidente de ellas es la que se deriva de la lengua objeto de análisis. Ninguna de las propuestas antes mencionadas tuvo como fin el estudio de la lengua china, lo que se refleja, por ejemplo, en la nómina y concreción de recursos lingüísticos. Ha sido necesario, por tanto, revisar dichas propuestas metodológicas y adaptarlas a las características tipológicas del chino. Así, por ejemplo, no resulta pertinente considerar la modificación morfológica interna o la modificación temporal del verbo, y en cambio sí lo es el uso de partículas 语气词 (yuqi $c i^{5}$, 'partículas modales') o la reduplicación.

Otro aspecto a considerar reside en el hecho de que el patrón de análisis utilizado por Blum-Kulka et alii (1989) se aplicó a un corpus obtenido mediante Discourse Completion Test (DCT, en lo que sigue), por lo tanto, algunos de los resultados obtenidos podrían estar condicionados por la metodología utilizada, y no por el ethos cultural de los hablantes. Así, en un corpus conversacional como el utilizado en este trabajo es previsible que el uso de actos de apoyo esté, de alguna forma, supeditado a la existencia de un contexto previo a la realización del acto de habla, y dicho contexto, o el conjunto de conocimientos compartidos, podría suplir su función. Una muestra de ello se observa en (7), el contexto en el que Chen Xun realiza la petición actuaría como justificación de la misma y, por tanto, a priori, no sería extraño que no apareciera el acto de apoyo. Asimismo, como consecuencia de la naturaleza conversacional del corpus, también es posible detectar el acto de apoyo en el siguiente turno de habla o, incluso, en el anterior (8).

(7) (Chen Xun y Fang Hui han tenido una discusión y han roto. En la calle, delante de la oficina de Fang Hui, Chen Xun despliega una pancarta que dice "te quiero". Fang Hui se asoma y la ve)

陈寻： 下来听我解释, 好不好

'Chen Xun: Baja y escucha mi explicación, ¿vale?'

(8) (El director Zeng es el jefe de Fang Hui. Él le ha enviado a la oficina un vestido de gran valor)

曾总:

方茴 换下衣服

跟我去参加一个重要会议

'Director Zeng: Fang Hui cámbiate de ropa

tienes que venir conmigo a una importante reunión'

$[\ldots \ldots]$

曾总:

今天这场合 不能再穿牛仔裤了

'Director A la reunión de hoy no puedes venir vestida con vaqueros'

Zeng:

5 No hay un único término para denominar estas partículas, por lo que es frecuente su referencia en la bibliografía como mood words, senteces particles o modal particles, pero en realidad tradicionalmente la lingüística china las incluye en la nómina de 虚词 ( $x u c i$, 'palabras vacías'). 
Por último, resulta plausible un uso cuantitativamente menor de alertadores que los obtenidos en un estudio que utilice DCT, pues el acto de habla puede realizarse en el transcurso de la conversación, por lo que, a priori, no sería tan necesario el uso de partículas para captar la atención del oyente, aunque quizá sí para mantenerla.

Dicho todo esto, en este trabajo se analiza el tipo de estrategia utilizada para realizar peticiones según la nómina establecida por Blum-Kulka et alii (1989: 278-281), y que ha sido muy frecuentemente utilizada en estudios posteriores, tanto para el chino como para otras lenguas (Zhang, 1995a; Lee-Wong, 1994; Rue y Zhan, 2008; Wang, 2011; entre otros). Sin embargo, es cierto también que con frecuencia los investigadores adaptan la nómina de estrategias propuesta por Blum-Kulka et alii (1989) a su propio criterio (Díaz, 2003; Siebold, 2008; Li, 2016). Este hecho, aunque teóricamente pudiera proporcionar una descripción más precisa de la realidad investigada, dificulta la comparación y extrapolación de los resultados. Para evitar esto, en este trabajo se toma como referencia la nómina de Blum-Kulka et alii (1989), sin alterarla, aunque sí se discutirá la idoneidad de continuar utilizándola.

La nómina de estrategias que se indican en Blum-Kulka et alii (1989: 278-281), y que afectan al núcleo del acto de habla, se ordena según su nivel de oblicuidad, desde las más directas a las más indirectas, o según su carácter impositivo en la terminología de Haverkate (1994).

1. Mood derivable ('derivable del modo oracional')

2. Explicit performative ('verbo performativo explícito')

3. Hedged performative ('verbo modal + verbo performativo')

4. Locution derivable ('derivable del contenido del enunciado')

5. Want statement ('expresión de deseo')

6. Suggestory formula ('fórmula de sugerencia')

7. Query preparatory ('condición preparatoria')

8. Unconventional indirect requests ('indirecta no convencionales') $)^{6}$

En la realización del acto de habla se pueden incluir, o no, recursos atenuadores o intensificadores. Este aspecto también se valoró en el presente trabajo, sin embargo, por las razones ya mencionadas, con respecto al fenómeno de la atenuación, se siguió la caracterización que ofrecen Briz y Albelda (2013).

una categoría pragmática en tanto que mecanismo estratégico y táctico (por tanto, intencional), que tiene que tiene que ver con la efectividad y eficacia del discurso, con el logro de los fines del discurso [...] dicha estrategia consiste en minorar, minimizar, mitigar, debilitar la acción e intención o efecto que estas puedan haber tenido en la interacción. (Briz y Albelda, 2013: 292-293).

\footnotetext{
6 Se ha incluido bajo este epígrafe los dos tipos de estrategias indirectas no convencionales (mild hint y strong hint) considerados por Blum-Kulka et alii (1989), entendiendo como tal la referencia no explícita al objeto de la petición.
} 
Específicamente, los recursos atenuadores valorados en este trabajo parten de las nóminas recogidas en Cestero y Albelda (2012) y Briz y Albelda (2013), y que habitualmente se utilizan para describir el habla de los hispanohablantes en diferentes tipos discursivos, entre ellos la conversación, y variedades geolectales (es.vag.atenuación) ${ }^{7}$.

1. Cuantificadores minimizadores

2. Selección léxica

3. Dilución de la responsabilidad de lo dicho mediante impersonalizaciones, apelación al juicio de la mayoría, recurrencia a presión o causa externa que motiva lo dicho, acotación de la opinión a la propia persona, etc.

4. Aserción en forma de duda o probabilidad

5. Fórmula de expresión de disculpa

6. Fórmula de expresión de agradecimiento

7. Atenuación de la fuerza ilocutiva mediante partículas finales

8. Fórmulas de cortesía para realizar peticiones

9. Expresión de fórmulas fácticas de petición de consentimiento

10. Utilización de oraciones interrogativas

11. Modificación del acto de habla que restringe lo dicho mediante construcciones sintácticas condicionales

12. Negación de la condición preparatoria

13. Reduplicación y repetición léxica

14. Utilización fórmulas de tratamiento de respeto

Bravo (2005: 32) y Briz y Albelda (2013: 292-295), entre otros, señalan que la atenuación solo es determinable contextualmente, de ahí que no resulte extraño que los recursos presentados en el listado anterior puedan pragmáticamente tener una función atenuadora, aunque no necesariamente en todos los contextos haya de ser así. Asimismo, Escandell (1995: 46) señalaba que «decir la verdad, toda la verdad, y nada más que la verdad no es un imperativo universal, sino, en todo caso, una norma vigente en algunas sociedades, ... y limitada, además, a ciertas situaciones». También en chino el uso pragmático atenuador de determinadas formas lingüísticas, como por ejemplo los cuantificadores minimizadores, evidencia dicha afirmación. Su uso atenuador está vinculado a los casos en los que el hablante, intencionadamente, bien no precisa el contenido, o bien no dice la verdad y la presenta de forma reducida. Por ejemplo, en (9) Jia Mo utiliza estratégicamente el cuantificador 点 (dian, 'un poco') para tratar de conseguir la rebaja del precio. Asimismo, (10) no debe interpretarse literalmente, es decir, no le está pidiendo que la próxima vez sea solo un poco más cuidadosa. Por el contrario, en (11) el jefe está demandando, literalmente, un pequeño reconocimiento público, no una gran ovación.

7 Aunque la prosodia también es un factor que se debe tener en cuenta a la hora de reconocer la atenuación o la intensificación, no se han incluido variables fónicas en el presente análisis, pues su estudio excede los propósitos de este trabajo. 
(9) (Jia Mo está intentando conseguir una reducción en el precio de los artículos que quiere comprar)

嘉茉: 你跟我便宜点, 六十吧

'Jia Mo: Me lo dejas un poco más barato, a sesenta PM'

(10) (La becaria, Amanda, ha cometido una importante equivocación en la realización del trabajo que se le había encomendado. Fang Hui, una de las protagonistas, ha conseguido solucionarlo a tiempo).

方茴: 你下次小心一点

'Fang Hui: la próxima vez sé un poco más cuidadosa'

(11) (Chen Xun ha tenido éxito en el trato con un importante cliente y el jefe de departamento pide un aplauso a los compañeros de oficina)

科长: 鼓掌, 鼓励一下

'Jefe de dep.: Un aplauso, un poco de ánimo'

De igual modo sucede con la reduplicación. Este mecanismo lingüístico, propio, aunque no exclusivo, de la lengua china, consiste en que «a morpheme is repeated so that the original morpheme together with its repetition form a new Word» (Li y Thompson, 1989: 28). Puede afectar a diferentes categorías lingüísticas y clases de palabra-verbos, adjetivos, clasificadores, términos de parentesco...- y, además, es uno de los mecanismos que habilita la lengua china para crear nuevos significados, por ejemplo, en el caso de un verbo como 看 (kan, 'ver/leer') vs. 看一看 (kan yi kan, 'echar un vistazo'). Al igual que sucede en castellano, es necesario conocer el contexto para determinar si esa forma reduplicada se ha usado, o no, con un valor atenuador, (12) vs. (13).

(12) 赵烨: 说说吧, 你俩怎么?

'Zhao Ye Cuenta, cuenta PM, ¿vosotros dos cómo estáis?'

(13) 嘉茉: 对了

方茴帮我看看

你觉得孙艺珍的这个发型适合我吗

'Jia Mo: Bien,

Fang Hui ayúdame y echa un vistazo a esto,

¿piensas que el estilo de peinado de Yi Zhen se me adaptaría?'

Es más, en el caso de que la reduplicación afecte a adjetivos o adverbios, no suele tener un efecto atenuador, sino intensificador. "When an adjetive is reduplicated as a noun modifier, the semantic effect is that the original meaning of the adjetive becomes more vivid» (Li y Thompson, 1989: 32). Algunas muestras de ello se observan en los siguientes ejemplos:

(14) 乔然： 那你好好休息 有什么事明天再说

'Qiao Ran: Entonces descansa bien bien mañana hablaremos' 
$\begin{array}{ll}\text { (15) 乔燃: } & \text { 你们等气消了 } \\ & \text { 好好聊一下 }\end{array}$

'Qiao Ran: Cuando os calméis,

Conversad bien bien un poco'

Pese a que la intensificación es una categoría menos estudiada que la de la atenuación y que parece que todavía no existe una concepción clara y uniforme del fenómeno, en los últimos años se está avanzando bastante en la formulación teórica de este concepto (Schneider, 2017). En este trabajo se parte de la caracterización que proponen Albelda (2014) y Briz (2017):

La intensificación, por tanto, es el valor comunicativo que se transmite mediante recursos lingüísticos que indican o advierten al oyente de que algo excede el curso normal de las cosas o de que él mismo exagera la realidad. (Albelda, 2014: 89)

intensificar es aumentar el grado de fuerza ilocutiva de las acciones que se llevan a cabo, así como reforzar el papel del yo y del tú (o de terceros), que quedan así más afectados por la acción [...] los intensificadores realzan la acción, la intención o punto de vista y, en consecuencia, la presencia del yo y, muchas veces, la afectación del tú o de una tercera persona en la acción que se realiza. (Briz, 2017: 44)

La gramática del chino (Chao, 1968; Li y Thomson, 1989) y el análisis de la muestra han permitido extraer una nómina de recursos susceptible de vehicular dicha función y que, lógicamente, estará condicionada por la tipología de la lengua objeto de análisis. Además, dado que se trata de un fenómeno solo determinable contextualmente, no sería extraño que el análisis de corpus más amplios contribuyera a aumentar esta nómina.

1. Modificadores de carácter adverbial (adverbios, locuciones, cuantificadores)

2. Reduplicación y repetición léxica

3. Partículas modales

4. Verbos exhortativos

5. Selección léxica

6. Estructuras sintácticas de énfasis: 是。。的 $(\text { shi..... de })^{8}$

7. Oraciones condicionales

En algunas investigaciones solo se valora el uso de atenuadores o intensificadores si estos aparecen en el núcleo de la petición (Blum-Kulka, et alii 1989; Díaz, 2003; Siebold, 2008). Escandell (2004: 187-188), sin embargo, considera que mitigadores e intensificadores pueden aparecer tanto en el núcleo como en los actos de apoyo. Según Escandell (2004: 187-188), la estructura interna de una petición no se compone solo del núcleo, sino que incluye también alertadores y actos apoyos, cada uno de los cuales a su vez es susceptible de incluir una serie de elementos, entre los que se encuentran atenuadores e intensificadores. Además, por su propia naturaleza, en las estrategias indirectas no convencionalizadas puede resultar difícil establecer límites precisos entre el núcleo y el resto de la estructura, y en consecuencia tam-

8 «addition of (shi)...de [...] to the native ears, gives these sentences an aura of firm conviction. (Shi) ... de may therefore be said to have the function of intensifying the speech act force of an utterance». (Han, 1988: 23) 
bién la decisión de contabilizar, o no, tales recursos. Por todo ello, en este estudio se considera la presencia de los recursos atenuadores e intensificadores en el conjunto del acto de habla.

Finalmente, se anotó la presencia, junto al núcleo del acto de habla, de supportive moves ('actos de apoyo') (Blum-Kulka et alii, 1989: 287-289) y alerters ('alertadores') (BlumKulka et alii, 1989: 277). Con respecto a los primeros, fue relevante observar no solamente la frecuencia con que estos aparecían, sino también su posición en la intervención -antepuesta o pospuesta al movimiento de apoyo- con el fin de determinar, si es que existe, el patrón discursivo propio y singular de los hablantes chinos.

Los alerters ('alertadores') se definen como palabras, de categorías variables, cuya función, formulados antes de la petición, es la de atraer la atención del otro interlocutor para dirigirla hacia el acto de habla. Se observó su presencia, así como también su tipología, para lo que nuevamente se tomó como referencia la nómina propuesta por Blum-Kulka et alii (1989: 277).

1. Título o rol profesional del oyente

2. Nombre de pila o apelativo amistoso del oyente

3. Saludo

4. Demostrativo

5. Expresión de disculpa

6. Expresión de cortesía

7. Marcador interpersonal

8. Combinación de varios de ellos

Antes de finalizar este apartado dedicado a la metodología, y para poder interpretar adecuadamente los resultados del análisis, es necesario especificar el tipo de relación existente entre los personajes. Se observan tres tipos de situaciones claramente diferenciadas:

a) las interacciones que se dan entre el grupo de amigos protagonistas (Fang Hui, Chen Xun, Jia Mo, Zhao Ye y Qiao Ran), que representan personas jóvenes a los que une una estrecha amistad (incluso algunos de ellos son pareja), con estudios medios o superiores y que se conocen desde el instituto

b) las interacciones que se dan entre el grupo de amigos protagonistas y sus respectivos superiores en el trabajo (jefe de departamento, director Zeng, presidente Kuang), entre los cuales, aunque la distancia social es también reducida, se observa una evidente asimetría en la relación de poder.

c) las interacciones en contextos, como por ejemplo, una tienda de ropa o un restaurante. En estas no existe un patrón tan unificado, pues no se observa una relación de poder tan asimétrica y la distancia social es muy variable, en función, por ejemplo, de si son clientes habituales o no. El conjunto de estas se ha identificado con el nombre "contextos transaccionales" y se ha representado en el grupo [+/- PS].

\section{PETICIONES}

Las peticiones se caracterizan semánticamente por el hecho de que, bajo formas o estrategias lingüísticas distintas ${ }^{9}$, el hablante intenta que el otro interlocutor realice una

9 «Request strategy is an obligatory choice of the level of directness by which the request is realized.» (BlumKulka et alii, 1989: 278) 
determinada acción en un futuro más o menos próximo: «they express the speaker's expectation of the hearer with regards to prospective action» (Blum-Kulka et alii, 1989: 11). Según la teoría de Brown y Levinson (1987: 65-67), se trata de un tipo de acto de habla amenazante para el oyente, pues en la medida en que el hablante condiciona la acción del oyente y aquel se beneficia de esta es la imagen del oyente la que podría interpretarse amenazada. Sin embargo, como se verá en este apartado, el contenido y fin de la petición pueden limitar la potencial amenaza que para el oyente supone (Brown y Levinson, 1987: 68-70); y, por otra parte, en determinados contextos es la imagen de ambos la que se compromete.

En las transcripciones se han detectado un total de 157 peticiones y la mayor parte de ellas se producen en interacciones entre interlocutores con una relación simétrica. Se observa también la tendencia a que en las relaciones asimétricas el participante con menor poder social no realice peticiones.

\begin{tabular}{|l|c|c|c|c|}
\cline { 2 - 5 } \multicolumn{1}{c|}{} & $\begin{array}{c}\text { Distancia social } \\
{[\mathrm{DS}]}\end{array}$ & $\begin{array}{c}\text { Poder social } \\
{[\mathrm{PS}]}\end{array}$ & $\mathrm{N}^{\mathrm{o}}$ & $\%$ \\
\cline { 2 - 5 } \multicolumn{1}{c|}{} & - & - & 79 & 50 \\
\hline Inferior-superior & - & + & 9 & 6,32 \\
\hline Superior-inferior & - & + & 43 & 27,84 \\
\hline & + & $+/-$ & 20 & 13,29 \\
\cline { 2 - 5 } & - & $+/-$ & 3 & 1,89 \\
\hline Total & & & 157 & 100 \\
\hline
\end{tabular}

Tabla 1. Relación entre realización del acto de habla de la petición y variables sociales.

El análisis de las estrategias utilizadas en dichas peticiones muestra la distribución seguidamente representada.

\begin{tabular}{|l|c|c|}
\hline Tipo de estrategia de petición & $\mathrm{N}^{\mathrm{o}}$ & $\%$ \\
\hline 1. Mood derivable ('derivable del modo oracional') & 120 & 76,43 \\
\hline 2. Explicit performative ('verbo performativo explícito') & 0 & 0,00 \\
\hline 3. Hedged performative ('verbo modal + verbo performativo') & 0 & 0,00 \\
\hline 4. Locution derivable ('derivable de la locución') & 12 & 7 \\
\hline 5. Want statement ('expresión de deseo') & 10 & 6,3 \\
\hline 6. Suggestory formula ('fórmula de sugerencia') & 0 & 0,00 \\
\hline 7. Query preparatory ('condición preparatoria') & 4 & 2,54 \\
\hline 8. Unconventional indirect requests ('indirecta no convencionales') & 12 & 7,64 \\
\hline Total & 157 & 100 \\
\hline
\end{tabular}

Tabla 2a. Tipología y frecuencia de estrategias en el acto de habla de la petición. 
En términos de frecuencia, es evidente que la estrategia considerada más directa es la que predomina ${ }^{10}$. Uno de los trabajos de referencia en el estudio de la petición en chino (Zhang, 1995a) mostraba un resultado distinto, y también algunos estudios contrastivos recientes (Padilla, 2016; Querol, 2016). Según Zhang (1995a), los hablantes chinos prefieren las estrategias indirectas convencionalizadas; en concreto, aquellas que denominaba query preparation ('condición preparatoria'), y que suelen contener verbos modales como 能 (neng, 'poder') y 可以 (keyi, 'es posible’). Dicho esto, quizá la interpretación de los resultados de un estudio como el de Zhang (1995a) exija considerar también la metodología utilizada, DCT. En este sentido, tal vez deba considerarse que trabajos como el de Zhang (1995a), Padilla (2016) o Querol (2016) lo que muestran no es tanto el habla real, sino la conciencia lingüística y pragmática de sus hablantes ${ }^{11}$.

\begin{tabular}{|c|c|c|c|c|c|c|c|c|c|c|}
\hline \multirow{2}{*}{$\begin{array}{l}\text { Estrategias de petición } \\
\text { en el núcleo del acto de } \\
\text { habla }\end{array}$} & - DS, & - PS & - DS, & $+\mathrm{PS}$ & - DS & $+\mathrm{PS}$ & $\begin{array}{c}+ \\
\text { DS, }\end{array}$ & $\begin{array}{l}+/- \\
\text { PS }\end{array}$ & -DS, & $\begin{array}{l}+/- \\
\text { PS } \\
\end{array}$ \\
\hline & $\mathrm{N}^{\mathrm{o}}$ & $\%$ & $\begin{array}{l}\text { (sup- } \\
\text { inf) } \\
\mathrm{N}^{\mathrm{o}}\end{array}$ & $\begin{array}{c}\text { (sup- } \\
\text { inf) } \\
\%\end{array}$ & $\begin{array}{l}\text { (inf- } \\
\text { sup) } \\
\mathrm{N}^{\mathrm{o}}\end{array}$ & $\begin{array}{l}\text { (inf- } \\
\text { sup) } \\
\%^{\circ}\end{array}$ & \multicolumn{2}{|l|}{$\mathrm{N}^{\mathrm{o}}$} & $\mathrm{N}^{\mathrm{o}}$ & $\%$ \\
\hline 1. Mood derivable & 65 & 41,40 & 38 & 24,20 & 7 & 4,46 & 7 & 4,46 & 3 & 1,91 \\
\hline 4. Locution derivable & 4 & 2,55 & 3 & 1,91 & 1 & 0,64 & 3 & 1,91 & 0,00 & 0,00 \\
\hline 5. Want statement & 2 & 1,27 & 0,00 & 0,00 & 0,00 & 0,00 & 7 & 4,46 & 0,00 & 0,00 \\
\hline 7. Query preparatory & 3 & 1,91 & 0,00 & 0,00 & 0,00 & 0,00 & 1 & 0,64 & 0,00 & 0,00 \\
\hline $\begin{array}{l}\text { 8. Unconventional indirect } \\
\text { requests }\end{array}$ & 7 & 4,46 & 3 & 1,91 & 2 & 1,27 & 0,00 & 0,00 & 0,00 & 0,00 \\
\hline Total & 78 & 49,68 & 44 & 28,03 & 10 & 6,37 & 17 & 10,83 & 3 & 1,91 \\
\hline
\end{tabular}

Tabla 2b. Tipología de estrategias en el acto de habla de la petición-variables sociales.

La preferencia por el uso de la estrategia más impositiva se evidencia en las peticiones realizadas por el interlocutor con mayor poder social, y también cuando no existe esa relación asimétrica. En los casos en los que quien realiza la petición tiene menor poder social la utilización de esta estrategia también es significativa, aunque, dado el reducido número de peticiones de ese tipo, no es posible realizar afirmaciones concluyentes. Resultados similares muestran Lee-Wong (1994, 2000), Tsuzuki et alii (2005), Wang (2011) y Li (2016) ${ }^{12}$, entre otros, lo que les lleva a afirmar que la imposición no es considerada

10 El análisis cualitativo no contemplará los resultados obtenidos en las estrategias que no han obtenido representatividad en el análisis de la muestra (explicit performative, suggestory formula, query preparatory y suggestory formula). Además, en adelante, para facilitar la lectura de los resultados, no aparecerán reflejadas en las tablas aquellas sobre las que no se ha registrado ningún ejemplo.

11 «Los nativos encuestados, a la hora de rellenar los test de situación, tienden a contestar de forma más o menos consciente con las respuestas que ellos consideran que serían más cotidianas en cada una de las situaciones establecidas. Son respuestas, por lo tanto, que tienden a ser más estereotipadas, debido al proceso de idealización por el que supuestamente se pasa al intentar rescribir un mensaje oral previamente emitido» (Ballesteros, 2001:187) $12 \mathrm{Li}$ (2016) lleva a cabo un estudio contrastivo español-chino del acto de habla de la petición. Para ello, analiza el corpus que forman diferentes otras literarias del s XX. Li (2016: 342-344) no solo concluye afirmando que en chino el modo imperativo y el uso de las estrategias directas es predominante en la realización de la petición, sino que su utilización es incluso ligeramente superior al de la muestra española. 
tan descortés e inapropiada en la sociedad china, especialmente entre iguales ${ }^{13}$. ¿Quiere decir esto que el estilo comunicativo chino tiene carácter directo e impositivo? ¿Son más impositivos incluso que los españoles? La respuesta no es tan obvia, puesto que, por ejemplo, casi en la mitad de ocasiones en las que los hablantes chinos de la muestra utilizaron la estrategia más impositiva lo hizo, al menos, con una estrategia atenuadora (v. tabla 3 ).

Las conclusiones del trabajo de Wang (2011) parecen indicar una clara interdependencia entre la estrategia de petición utilizada y la relación de poder y distancia social entre los interlocutores ${ }^{14}$; sin embargo, y sin negar la importancia de este factor, en este trabajo se ha detectado que otras cuestiones, como la temática de la petición o el beneficiario de la petición requerida, son igualmente decisivas y no suelen ser consideradas. Por ejemplo, en los capítulos analizados se observa la reiterada utilización de la estrategia indirecta no convencionalizada en dos situaciones muy concretas: a) cuando el grupo de jóvenes protagonistas habla de la violación de Fang Hui y se le pide que lo olvide (15), (16); y b) cuando se solicita algo que, dada la relación existente entre los interlocutores, podría exceder los límites de lo que se considera prescriptivo (17).

(15) 赵烨:

'Zhao Ye:

(16) 陈寻:

'Chen Xun:

(17) 曾总:

过去的事, 说重要也重要

说不重要也就是吹口气就没了的事

Sobre el asunto del pasado, lo que es importante es importante, lo que no es importante puede desaparecer con un solo suspiro'

我们不要用过去的错误来惩自己, 行吗?

No queremos que nuestros errores del pasado nos atormenten, ¿cierto?'

她之前根你一样, 就是一个小小的AE

只是因为在我身边待了一年就拥有了相当于三年的人脉积累和沟通 经验成了猎头公司的首先目标

我希望你明白

做人有自己的原则没有错, 但是大部分的生意都是在酒桌上谈成的 做人要学会随机应变

'Director Zeng: Ella antes era como tú, solo era una secretaria

después de solo un año a mi lado un año ha conseguido lo que se tarda 3 años, contactos y experiencia en comunicación. Se ha convertido en el principal objetivo de las empresas cazatalentos

yo espero que me entiendas

tener principios no está mal, pero la mayoría de negocios se hacen en una mesa con alcohol

hay que aprender a adaptarse'

13 «imposition is not considered so impolite and inappropriate in Chinese society, especially for the close and equal relationship» (Tsuzuki et alii, 2005: 293).

14 Según Wang (2011), en aquellas situaciones en las que el destinatario de la petición tiene mayor poder que el que la realiza predomina claramente la estrategia de condición preparatoria, y, por el contrario, en los casos en los que el destinatario tiene menor poder predominan las estrategias directas como son las derivadas de la utilización de modo imperativo o verbos performativos. Estas estrategias prevalecen también en aquellas situaciones en las que ambos interlocutores ostentan un poder social semejante (excepto en aquellos casos en los que existe una gran distancia social entre los interlocutores, en los que vuelve a predominar el uso de la estrategia condición preparatoria). 
Por el contrario, en los casos en los que se solicita que el oyente se quede con ropa nueva de forma gratuita o que se vaya a casa antes de finalizar su jornada laboral, independientemente de la relación social existente entre los interlocutores, se utiliza el modo imperativo sin ningún tipo de atenuación, y además no parece que esto sea pragmáticamente inadecuado. No necesariamente se trata de casos en los que se solicita algo con poca trascendencia o en los que el grado de intimidad entre los interlocutores sea especialmente alto, sino peticiones en las cuales es evidente el beneficio que obtiene el oyente al realizar la acción demandada y que a su vez no requieren grandes sacrificios por parte del hablante (18) (Brown y Levinson, 1987: 68-70) ${ }^{15}$.

(18) (Fang Hui está ojeando algunas de las prendas que Jia Mo tiene a la venta)

嘉茉: 看好了随便拿反正我也卖是不出去

'Jia Mo: Bien, coge lo que quieras, en cualquier caso no lo vendo'

Por último, es pertinente apuntar el hecho de que la estrategia de expresión de deseo se ha dado, de forma prácticamente exclusiva, en los contextos transaccionales en los que los interlocutores apenas se conocían (19). Pese a ello, también en este grupo la estrategia más directa es la que predomina en la realización de peticiones. La investigación de Pan (2000: 25-52), basada en el examen de 22 peticiones realizadas en cantonés en una tienda de sellos, señala también que en el contexto chino en los "encuentros de servicio" las peticiones se realizan frecuentemente mediante la fórmula básica de imperativo (verbo + objeto) sin marca alguna de cortesía. Por tanto, su conclusión es que para los chinos no hay necesidad de reducir el grado de oblicuidad de la petición cuando la relación entre los participantes es externa y marcada como + DS.

\section{(19) 嘉茉: 我都要了你给我便宜点吧}

'Jia Mo: Yo lo quiero todo, entonces tú me lo dejarás un poco más barato PM'

En resumen, en este apartado se ha mostrado la preferencia de los hablantes chinos por el uso de la estrategia más impositiva para realizar peticiones en el contexto conversacional oral. Sin embargo, se ha anotado también cómo la preferencia por una determinada estrategia, no solo está condicionada por el ethos cultural de sus hablantes, sino también por el tipo de discursivo y el resto de elementos lingüísticos que la acompañan, así como también por la relación social (PS, DS) existente entre los hablantes y la temática y repercusión de la petición.

\subsection{Atenuación en el acto de habla de la petición}

El uso de atenuadores junto a la petición supone la elección de una estrategia pragmática en la que el hablante trata de reducir el posible efecto negativo del contenido proposicional o de la fuerza ilocutiva del acto utilizando una serie de recursos lingüísticos y paralingüísticos. El análisis muestra que el 40,76\% (64/157) de las peticiones contenía algún recurso

15 Se trata de algunos de los motivos que Brown y Levinson (1987: 68-70) consideraban para explicar que el hablante pudiera realizar un acto potencialmente amenazante sin atender a la imagen del oyente «Doing an act baldly, without redress». 
atenuador, aunque solo el 5,10 \% (8/157) contenía más de uno. Si se analiza el uso de la atenuación en relación con el tipo de estrategia para realizar la petición, se constata también que las estrategias más impositivas tienen bastantes probabilidades de ser atenuadas. En este sentido, en la tabla 3 se representan específicamente las probabilidades, según la muestra estudiada, de que aparezca, al menos, un recurso atenuador en cada uno de los tipos de estrategia. En las tablas $4 a$ y $4 b$, en cambio, se registra la frecuencia de aparición de los diferentes recursos atenuadores en cada una de las estrategias.

\begin{tabular}{|l|c|c|c|}
\hline \multicolumn{1}{c|}{$\begin{array}{c}\text { Estrategias de petición } \\
\text { en el núcleo } \\
\text { del acto de habla }\end{array}$} & $\mathrm{N}^{\mathrm{o}}$ & $\begin{array}{c}\text { Recursos atenuadores } \\
\text { En la estrategia } \\
\%\end{array}$ & $\begin{array}{c}\text { Frec. } \\
\text { Absoluta } \\
\%\end{array}$ \\
\cline { 2 - 4 } & 49 & 40,83 & 31,21 \\
\hline 1. Mood derivable & 5 & 45,45 & 3,18 \\
\hline 4. Locution derivable & 2 & 20,00 & 1,27 \\
\hline 5. Want statement & 2 & 50,00 & 1,27 \\
\hline 7. Query preparatory & 6 & 50,00 & 3,82 \\
\hline 8. Unconventional indirect requests & 64 & 100,00 & 40,76 \\
\hline Total & & & \\
\hline
\end{tabular}

Tabla 3. Estrategias en el acto de habla de la petición-frecuencia de recursos atenuadores.

Dicho esto, nuevamente sería pertinente considerar que el valor impositivo de una petición no viene determinado únicamente por la estrategia utilizada en el núcleo, sino por el conjunto de recursos existentes en ella. Así pues, determinar si los chinos son más o menos impositivos en sus peticiones que los hablantes de otras comunidades lingüísticas exigiría comparar y contrastar todo ello. Por otra parte, también cabe reflexionar sobre el hecho de que las estrategias menos impositivas en la nómina de Blum-Kulka et alii (1989) lo son porque se forman a partir de recursos atenuadores. Por ejemplo, el uso de la pregunta 怎 么样 (Zenme yang, ‘qqué tal si...?’) en la estrategia de fórmula de sugerencia (20) o el uso de los verbos modales 可以 (ke yi, 'es posible') 能 (neng, 'poder') en la estrategia de condición preparatoria (21).

减到十页怎么样?

(21) 方茴：陈寻你可不可以让我冷静一下

‘QQué tal reducir 10 páginas?’ (Zhang, 1995ª: 45)

'Fang Hui: ¿Chen Xun podrías o no dejar que me calme un poco?'

Si esto es así, ¿no deberían también ser contabilizados como recursos atenuadores? ¿por qué mantener esa distinción entre los recursos atenuadores? Ante esta situación, cabe preguntarse si, metodológicamente, no sería más adecuado la identificación onosemasiológica del tipo de acto de habla y, a continuación, de todos los recursos atenuadores presentes, entre los que se incluirían verbos modales, fórmulas de sugerencia o la propia oración interrogativa ${ }^{16}$.

16 En algunas investigaciones (Siebold, 2008; Querol, 2016), la oración interrogativa aparece en la nómina de estrategias de petición. 
De una forma similar a esta se lleva a cabo la investigación de Contreras y Zhao (2017). En esta se valoran y comparan de forma conjunta todos los recursos atenuadores utilizados en actos de habla directivos en correos electrónicos enviados por estudiantes españoles, alemanes y chinos a sus respectivos profesores. Entre sus resultados se observa que son los hablantes chinos los que menos recursos atenuadores utilizan, menos incluso que los españoles.

Con respecto a la tipología de recursos atenuadores, la muestra analizada evidencia la preferencia por algunos de ellos: en primer lugar, las partículas modales; y en segundo lugar, la reduplicación y los cuantificadores minimizadores.

\begin{tabular}{|l|c|c|c|c|c|c|c|c|c|c|}
\hline \multirow{2}{*}{$\begin{array}{l}\text { Estrategias de petición } \\
\text { en el núcleo } \\
\text { del acto de habla }\end{array}$} & \multicolumn{2}{|c|}{$1^{17}$} & \multicolumn{2}{|c|}{2} & \multicolumn{2}{|c|}{3} & \multicolumn{3}{|c|}{5} & \multicolumn{2}{|c|}{7} \\
\cline { 2 - 14 } & $\mathrm{N}^{\mathrm{o}}$ & $\%$ & $\mathrm{~N}^{\mathrm{o}}$ & $\%$ & $\mathrm{~N}^{\mathrm{o}}$ & $\%$ & $\mathrm{~N}^{\mathrm{o}}$ & $\%$ & $\mathrm{~N}^{\mathrm{o}}$ & $\%$ \\
\hline 1. Mood derivable & 13 & 17,57 & 4 & 5,41 & 0 & 0,00 & 20 & 27,03 & 0 & 0,00 \\
\hline 4. Locution derivable & 1 & 1,35 & 0 & 0,00 & 1 & 1,35 & 2 & 2,70 & 0 & 0,00 \\
\hline 5. Want statement & 1 & 1,35 & 0 & 0,00 & 1 & 1,35 & 1 & 1,35 & 0 & 0,00 \\
\hline 7. Query preparatory & 1 & 1,35 & 0 & 0,00 & 0 & 0,00 & 0 & 0,00 & 0 & 0,00 \\
\hline $\begin{array}{l}\text { 8. Unconventional } \\
\text { indirect requests }\end{array}$ & 0 & 0,00 & 1 & 1,35 & 1 & 1,35 & 1 & 1,35 & 1 & 1,35 \\
\hline Total & 16 & 21,62 & 5 & 6,76 & 3 & 4,05 & 24 & 32,43 & 1 & 1,35 \\
\hline
\end{tabular}

Tabla 4a: Estrategias en el acto de habla de la petición-tipología de recursos atenuadores.

\begin{tabular}{|l|c|c|c|c|c|c|c|c|}
\hline \multirow{2}{*}{$\begin{array}{l}\text { Estrategias de petición } \\
\text { en el núcleo } \\
\text { del acto de habla }\end{array}$} & \multicolumn{2}{|c|}{9} & \multicolumn{2}{|c|}{11} & \multicolumn{2}{|c|}{12} & \multicolumn{2}{|c|}{13} \\
\cline { 2 - 10 } & $\mathrm{N}^{\mathrm{o}}$ & $\%$ & $\mathrm{~N}^{\mathrm{o}}$ & & $\mathrm{N}^{\mathrm{o}}$ & $\%$ & $\mathrm{~N}^{\circ}$ & $\%$ \\
\hline 1. Mood derivable & 3 & 4,05 & 1 & 1,35 & 0 & 0,00 & 14 & 18,92 \\
\hline 4. Locution derivable & 0 & 0,00 & 0 & 0,00 & 1 & 1,35 & 1 & 1,35 \\
\hline 5. Want statement & 0 & 0,00 & 0 & 0,00 & 0 & 0,00 & 0 & 0,00 \\
\hline 7. Query preparatory & 0 & 0,00 & 0 & 0,00 & 1 & 1,35 & 0 & 0,00 \\
\hline $\begin{array}{l}\text { 8. Unconventional } \\
\text { indirect requests }\end{array}$ & 1 & 1,35 & 1 & 1,35 & 1 & 1,35 & 1 & 1,35 \\
\hline Total & 4 & 5,41 & 2 & 2,70 & 3 & 4,05 & 16 & 21,62 \\
\hline
\end{tabular}

Tabla 4b: Estrategias en el acto de habla de la petición-tipología de recursos atenuadores.

Las partículas modales 语气词 (yuqi ci), que tradicionalmente la lingüística china las incluye en la nómina de 虚词 (xuci, 'caracteres vacíos'), comparten una serie una serie de propiedades fónicas, sintácticas, léxicas y también pragmáticas (Chao, 1968; Hang, 1988). Por ejemplo, su uso no es imprescindible para la gramaticalidad del enunciado, sin embargo, cuando se utilizan, especialmente en un acto de habla amenazante, este se marca como

17 La numeración corresponde al recurso atenuador presentado en el apartado 2. Aquellos recursos que no se registraron en la muestra no aparecen contemplados en la tabla. 
+ cortés. Dichas semejanzas no implican que su caracterización semántica o pragmática sea necesariamente idéntica; algunas, como p. ej., 吧 (ba), pueden usarse como recursos atenuadores; y otras, como p. ej., 啊 (a), pueden utilizarse como recursos intensificadores (Wang, 2013; Querol (en prensa)). Por otra parte, dado que el uso de estas partículas es propio de contextos conversacionales orales, no es de extrañar que su recurrencia en un corpus realizado a partir de la transcripción de conversaciones sea mayor que la contabilizada en otras investigaciones que utilicen, por ejemplo, DCT como metodología o fuentes escritas como corpus. En consecuencia, el uso y contraste de la atenuación chino-español también ha de ser puesto en relación con los diferentes tipos discursivos.

La partícula con uso atenuador con mayor recurrencia en el corpus es 吧 $(b a)$. Precisamente uno de los principales usos de esta partícula consiste en incluirse al final de la petición, de tal forma que esta, aunque tuviera la forma de orden o mandato, adquiere la de "sugerencia", es decir, la utilización de esta partícula contribuye a reducir la fuerza del acto ilocutivo (Chao, 1968; Han, 1988; Li y Thompson, 1989; Lee-Wong, 1998). Este uso de la partícula 吧 $(b a)$ se reconoce claramente mediante la comparación de (22) y (23). Ambos tienen la misma estructura sintáctica, sin embargo, el efecto pragmático es muy diferente. En (22) el director Zeng realiza una petición a Fang Hui en forma de orden expresada en imperativo, sin ningún tipo de atenuante y con un tono y volumen que contribuyen a intensificarla. En (23), en cambio, el acto de apoyo que precede a la petición, expresada también en forma imperativa, y la partícula 吧 ( $b a)$ contribuyen a suavizar su fuerza ilocutiva.

(22) (Cuando el director Zeng ha intentado abrazar a Fang Hui en una reunión en una discoteca, Fang Hui se marcha.)

曾总：方茴 站住

'Director Zeng: Fang Hui detente'

(23) (Es de noche y Fang Hui va caminado sola por la calle de vuelta a la oficina.)

曾总：你就打算穿成这样走回去吗 上车吧

'Director ¿Has pensado volver a casa así vestida?

Zeng: $\quad$ Sube al coche PM'

En términos cuantitativos, los otros recursos atenuadores con mayor recursividad son la reduplicación y el uso de cuantificadores minimizadores, fundamentalmente 一下 (yi xia, 'un poco') e 一点 (yi dian, 'un poco').

(24) (Jia Mo está intentando conseguir una reducción en el precio de las prendas de ropa que quiere comprar)

嘉莱: 你跟我便宜点, 六十吧

'Jia Mo: Me las dejas un poco más baratas, a sesenta PM'

(25) (La becaria, Amanda, ha cometido una importante equivocación en la realización del trabajo que se le había encomendado, pero Fang Hui ha conseguido solucionarlo a tiempo).

方茴：你不次小心一点

'Fang Hui: La próxima vez sé un poco más cuidadosa' 
Por último, con respecto a las funciones de la atenuación en el acto de habla de la petición, parece lógico pensar que la mayoría de los ejemplos apunten a la función de prevención, «una estrategia para prevenir posibles daños a la imagen o problemas por la intromisión o invasión del territorio o espacio del otro, un modo este de evitar tensiones y conflictos (por tanto salvaguarda del yo y del tú)» (Briz y Albelda, 2013: 302-303). Este uso se observa con claridad, por ejemplo, en las muestras (17) y (25). Dicho esto, es relevante destacar que dicha prevención no solo actúa con respecto al oyente, sino también con respecto al hablante, pues, por ejemplo, si la petición es rechazada o denegada ¿no se interpretaría que es culpa del hablante por realizar una petición no adecuada? ¿la imagen de quién se vería entonces más afectada? Se trata, por tanto, de usos corteses de la atenuación en la petición, y el "quedar bien" que define a la cortesía conlleva la implicación de ambas imágenes (Bravo, 2005: 32-35).

\subsection{Intensificación en el acto de habla de la petición}

Pese a que, como ya se ha mencionado anteriormente, la intensificación ha recibido hasta ahora una menor atención por parte de los investigadores, sí existen algunas referencias a su uso y concreción en las peticiones realizadas por hablantes chinos.

Zhang (1995a: 56) indica la poca frecuencia con que este recurso es utilizado en las peticiones en chino; de hacerlo, son los que denomina "intensificadores de tiempo"18 los que tienen un mayor uso, especialmente en peticiones realizadas entre iguales. Sin embargo, Li (2016: 121), que contempla dos tipos de recursos intensificadores -reiteración de la petición e intensificadores de tiempo-, indica explícitamente que la única estrategia que puede aumentar la fuerza ilocutiva es la reiteración de la petición (aunque en su análisis ambos recursos tienen representación muy próxima, 6,8\% vs. 5,2 \%).

Por otra parte, Li (2015) muestra que los hablantes chinos prefieren el uso de intensificadores en situaciones en las que el que realiza la petición tiene mayor poder social (+PS), y en estas el tipo más frecuente es un intensificador adverbial, como por ejemplo 我真的很 希望... ... (wo zhen de hen xiwang, 'yo verdaderamente espero que...'), que expresa la esperanza de que el receptor cumpla la petición ( $\mathrm{Li}, 2015: 446)$.

Finalmente, Rue y Zhang (2008: 197) señalan la preferencia, tanto de los hablantes chinos como de los hablantes coreanos, por el recurso de la repetición como mecanismo léxico intensificador, ${ }^{19}$ aunque los hablantes chinos los suelen utilizar solo para dirigirse a familiares.

Dicho todo esto, se muestra a continuación la nómina y frecuencia de los recursos intensificadores registrados en el análisis. En la tabla 5 se anota el número de peticiones en las que aparece algún recurso intensificador y lo que porcentualmente ello implica en el conjunto de peticiones registrado, en cada estrategia y en el total de la muestra. En la tabla 6, en cambio, se refleja la aparición de cada uno de los recursos intensificadores, así como el valor porcentual de dicho recurso en el conjunto de la muestra.

18 Con dicho término se refieren a frases o expresiones que indican la urgencia de la petición, como por ejemplo 马上 (mashang, 'inmediatamente') o 赶紧 (ganjin, 'apresuradamente') (Zhang (1995a: 56; Rue y Zhang, 2008: 43). 19 En Rue y Zhang (2008) únicamente se valora el uso de los que los autores consideran lexical upgraders (repetition of request, time intensifier y commitment indicator), es decir, no se consideran intensificadores de carácter sintáctico. Una decisión probablemente motivada por las características tipológicas de ambas y que, por tanto, no puede ser mantenida si la comparación o los resultados se plantean con respecto a otras lenguas. 


\begin{tabular}{|l|c|c|c|}
\hline \multirow{2}{*}{$\begin{array}{l}\text { Estrategias de petición } \\
\text { en el núcleo del acto de habla }\end{array}$} & \multicolumn{3}{|c|}{$\begin{array}{c}\text { Recursos } \\
\text { intensificadores }\end{array}$} \\
\cline { 2 - 4 } & $\mathrm{N}^{\mathrm{O}}$ & $\begin{array}{c}\text { Frec } \\
\text { en estrategia } \\
\%\end{array}$ & $\begin{array}{c}\text { Frec. } \\
\text { Absoluta } \\
\%\end{array}$ \\
\hline 1. Mood derivable & 30 & 25,00 & 18,47 \\
\hline 4. Locution derivable & 3 & 27,27 & 1,91 \\
\hline 5. Want statement & 1 & 10 & 0,64 \\
\hline 7. Query preparatory & 1 & 25 & 0,64 \\
\hline 8. Unconventional indirect requests & 1 & 8,33 & 0,64 \\
\hline Total & 36 & & 24,20 \\
\hline
\end{tabular}

Tabla 5: Estrategias en el acto de habla de la petición-frecuencia de los recursos intensificadores.

\begin{tabular}{|l|c|c|}
\hline Tipología de recursos intensificadores & $\mathrm{N}^{\circ}$ & $\%$ \\
\hline $\begin{array}{l}\text { Modificadores de carácter adverbial } \\
\text { (adverbios, locuciones, cuantificadores) }\end{array}$ & 13 & 32,50 \\
\hline 2. Reduplicación y repetición léxica & 6 & 15,00 \\
\hline 3. Partículas modales & 16 & 40,00 \\
\hline 4. Verbos exhortativos & 2 & 5,00 \\
\hline 5. Selección léxica & 1 & 2,50 \\
\hline 6. Estructuras sintácticas de énfasis: 是 。。的 (shi.....de) & 0 & 0,00 \\
\hline 7. Oraciones condicionales & 2 & 5,00 \\
\hline Total & 40 & 32,50 \\
\hline
\end{tabular}

Tabla 6: Tipología y frecuencia de los recursos intensificadores en el acto de habla de la petición.

Con respecto a la tipología de recursos intensificadores, nuevamente se observa la productividad de las partículas modales, en concreto, de la partícula 啊 ( $a$ ) (o sus variantes alofónicas, v. Wang, 2013:8-9)20; incluso, tal y como señalaba Wang (2013: 137), no es extraño que coaparezca con otros recursos intensificadores (26).

20 En el ámbito académico existe una importante discusión sobre el uso y función de la partícula 啊 (a). En torno a su caracterización existen dos posiciones antagónicas: por una parte, autores que como Chao (1968: 803-806), Li y Thompson (1989) o Lee-Wong (1998) le otorgan un valor atenuador y cortés; y, por otra parte, autores que como Han (1988: 28), o la propia Wang (2013) consideran su valor intensificador. Resolver dicha cuestión exige desligar, tal y como indican Albelda (2005), Bravo (2005) o Briz (2012), los conceptos de atenuación-cortesía vs. intensificación-descortesía. Por tanto, la partícula 啊 (a) es una estrategia pragmática intensificadora que puede contribuir a incrementar la cortesía del enunciado. 
(26) 阿曼达: 工作上的事情我们也都能理解 你可千万别往心里去啊

'Amanda: Son asuntos de trabajo, todos también lo podemos entender tú no deberías en ningún caso tomártelo muy profundamente (muy a pecho) PM'

Los modificadores de carácter adverbial tienen una alta productividad como recursos intensificadores. En este trabajo se han incluido en esta categoría los "intensificadores de tiempo" de los que hablaba Zhang (1995a: 56), que incluso pueden aparecer simultáneamente (27), pero también los modificadores con significado de modal, como por ejemplo 千万 (qianwan, 'por todos los medios') (29). Probablemente la frecuencia de este tipo de intensificadores se deba, nuevamente, al tipo de corpus y de discurso examinado (DCT vs. análisis conversacional, escrito vs. oral, etc.).

(27) 嘉茉:

跟我回家 立该马上秒钟

'Jia Mo: Vamos a casa inmediatamente ya en este segundo'

(28) 曾总:

马上联系到打她

'Director

'inmediatamente conecta con ella por teléfono'

Zeng:

(29) 嘉茉:

在发型问题上你千万别冲动

我到现在都还记得 你上高中时候那个方便面头

'Jia Mo: Con las cuestiones de estilo procura por todos los medios no ser impulsiva yo todavía recuerdo tu pelo de fideo durante la secundaria'

Ejemplos de otras estrategias intensificadoras detectadas en el corpus se muestran a continuación:

(30) 科长:

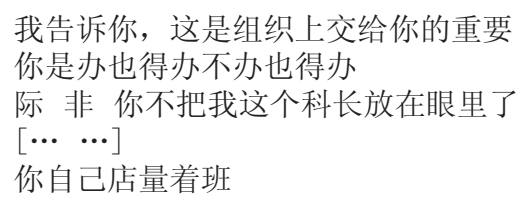

'Jefe de dep.: Te lo advierto, esto para la organización es muy importante si te gusta o no da lo mismo tienes que hacerlo a menos que no me respetes como tu jefe de sección $[\ldots]$ considera tú mismo tus opciones'

(31) 科长: 你好好陪我老大玩啊

'Jefe de dep.: Acompaña bien bien al jefe y que se divierta PM'

Por último, cabe observar cierta relación entre el uso de intensificadores y la variable [+PS] (v. tabla 7) que favorece su utilización. 


\begin{tabular}{|l|c|c|c|c|c|c|c|}
\cline { 3 - 8 } \multicolumn{1}{c|}{} & \multicolumn{2}{c|}{} & \multicolumn{2}{c|}{ Petición } & \multicolumn{3}{c|}{ Intensificación } \\
\cline { 2 - 8 } \multicolumn{1}{c|}{} & DS & PS & $\mathrm{N}^{\mathbf{0}}$ & $\%$ & $\mathrm{~N}^{\circ}$ & $\begin{array}{c}\text { En la variable social } \\
\%\end{array}$ & $\begin{array}{c}\text { Absoluta } \\
\%\end{array}$ \\
\cline { 2 - 8 } \multicolumn{1}{c|}{} & - & - & 79 & 50 & 15 & 18,99 & 9,55 \\
\hline Inferior-superior & - & + & 9 & 6,32 & 2 & 22,22 & 1,27 \\
\hline Superior-inferior & - & + & 43 & 27,84 & 15 & 34,88 & 9,55 \\
\hline & + & $+/-$ & 20 & 13,29 & 3 & 15,00 & 1,91 \\
\cline { 2 - 8 } & - & $+/-$ & 3 & 1,89 & 0 & 0,00 & 0,00 \\
\hline Total & & & 157 & 100 & 36 & 22,93 & 22,93 \\
\hline
\end{tabular}

Tabla 7. Variables sociales-recursos intensificadores en el acto de habla de la petición.

\subsection{Actos de apoyo y alertadores en el acto de habla de la petición}

Como se observa en la tabla 8 , la estrategia más directa tiene más probabilidades de que la petición se acompañe de, al menos, un acto de apoyo, incluso en contextos conversacionales en los que el contexto o el conjunto de conocimientos compartidos permitirían su elisión. Es más, el 28, $33 \%(34 / 120)$ de las peticiones que utilizan la estrategia 1 no contenía ningún recurso atenuador o acto de apoyo.

\begin{tabular}{|c|c|c|c|c|c|c|c|c|c|c|c|c|c|c|}
\hline \multirow{3}{*}{$\begin{array}{l}\text { Estrategias de peti- } \\
\text { ción en el núcleo del } \\
\text { acto de habla }\end{array}$} & \multicolumn{14}{|c|}{ Actos De Apoyo } \\
\hline & \multicolumn{2}{|c|}{$\mathrm{A} 1^{21}$} & \multicolumn{2}{|c|}{$\mathrm{A} \leq 2$} & \multicolumn{2}{|c|}{$\mathrm{P} 1$} & \multicolumn{2}{|c|}{$\mathrm{P} \leq 2$} & \multicolumn{2}{|c|}{$\mathrm{A} 1+\mathrm{P} 1$} & \multicolumn{2}{|c|}{$\mathrm{A} 1+\mathrm{P} \leq 2$} & \multicolumn{2}{|c|}{ Total } \\
\hline & $\mathrm{N}^{\mathrm{o}}$ & $\%$ & $\mathrm{~N}^{\mathrm{o}}$ & $\%$ & $\mathrm{~N}^{\circ}$ & $\%$ & $\mathrm{~N}^{\mathrm{o}}$ & $\%$ & $\mathrm{~N}^{\mathrm{o}}$ & $\%$ & $\mathrm{~N}^{\circ}$ & $\%$ & $\mathrm{~N}^{\circ}$ & $\%$ \\
\hline 1. Mood derivable & 19 & 12,10 & 2 & 1,27 & 38 & 24,20 & 5 & 3,18 & 2 & 1,27 & 0 & 0,00 & 66 & 42,04 \\
\hline 4. Locution derivable & 1 & 0,64 & 1 & 0,64 & 0 & 0,00 & 0 & 0,00 & 0 & 0,00 & 3 & 1,91 & 5 & 3,18 \\
\hline 5. Want statement & 1 & 0,64 & 1 & 0,64 & 1 & 0,64 & 0 & 0,00 & 0 & 0,00 & 0 & 0,00 & 3 & 1,91 \\
\hline 7. Query preparatory & 1 & 0,64 & 0 & 0,00 & 0 & 0,00 & 0 & 0,00 & 0 & 0,00 & 0 & 0,00 & 1 & 0,64 \\
\hline $\begin{array}{l}\text { 8. Unconventional } \\
\text { indirect requests }\end{array}$ & 2 & 1,27 & 0 & 0,00 & 1 & 0,64 & 1 & 0,64 & 2 & 1,27 & 0 & 0,00 & 6 & 3,82 \\
\hline Total & 24 & 15,29 & 4 & 2,55 & 40 & 25,48 & 6 & 3,82 & 4 & 2,55 & 3 & 1,91 & 81 & 51,59 \\
\hline
\end{tabular}

Tabla 8. Frecuencia y posición del acto de apoyo en el acto de habla de la petición.

21 Leyenda:

A (antepuesto), P (pospuesto).

El número indica la cantidad de actos de apoyo.

El porcentaje indica la probabilidad de aparición en el conjunto de peticiones de la muestra. 
El contenido de estos actos de apoyo suelen ser justificaciones o excusas, por lo que podrían, desde el punto de vista pragmático, considerarse una estrategia argumentativa que contribuye a reducir el carácter impositivo del acto de habla y, por tanto, recursos atenuadores a nivel discursivo ${ }^{22}$. Por ejemplo, en (32) el director Zeng pide reiteradamente a Fang Hui que se suba al coche para llevarla de vuelta a la oficina. Pese a ostentar una clara posición de [+PS] y utilizar el imperativo, la fuerza ilocutiva de la petición se reduce considerablemente al acompañarla de actos de apoyo que tratan de justificarla y de recursos atenuantes como la partícula 吧 $(b a)$. Así pues, posiblemente el uso de los actos de apoyo tenga más que ver con el empleo de estrategias pragmáticas para lograr determinados fines comunicativos, que con la codificación y descodificación del mensaje.

$\begin{array}{ll}\text { (32) 曾总: } & \text { 方茴 上车吧 } \\ \text { 'Director Zeng: } & \text { Fang Hui sube al coche PM' } \\ \text { 方茴: } & \text { 不用 我打车 } \\ \text { 'Fang Hui: } & \text { No hace falta cogeré un taxi' } \\ \text { 曾总: } & \text { 这儿晚，你打着车就见鬼了 } \\ \text { 'Director Zeng: } & \text { Es de noche, si subes al taxi verás al demonio (es peligroso)' } \\ \text { 方茴: } & \text { 不劳您费心 } \\ \text { 'Fang Hui } & \text { No quiero molestarle' } \\ \text { 曾总: } & \text { 你就打算穿成这样走回去吗 } \\ & \text { 上车吧 } \\ \text { 'Director Zeng: } & \text { ¿Has pensado volver a casa así vestida? } \\ & \text { sube al coche PM' }\end{array}$

En términos absolutos, la mayor parte de los actos de apoyo identificados aparecen a continuación del núcleo de la petición, realizada, además, mediante la estrategia más directa posible. Este resultado contrasta con los resultados obtenidos en otras investigaciones, que indican que en la retórica china la estrategia habitual es ofrecer al oyente las razones y justificaciones pertinentes antes de formular la petición (Kirpatrick, 1991; Kirpatrick, 1995; Chen, 2001). Nuevamente es necesario apelar a la metodología y tipo de corpus utilizado (oral vs. escrito, análisis conversacional vs. DCT) para interpretar los resultados, y en consecuencia acotarlos a determinados tipos discursivos.

Por otra parte, se observa que solo el 25,48 \% (40/157) de las peticiones contiene algún tipo de alertador. Este resultado corrobora la hipótesis inicial, según la cual, su presencia en corpus conversacionales es mucho menor que la obtenida en investigaciones que utilicen DCT como metodología.

Según su tipología, los alertadores que indican el nombre de pila (o apelativo amistoso) y aquellos que indican el título o categoría profesional son los que muestran mayor recurrencia. No se registran, en cambio, alertadores tipo saludo, agradecimiento o fórmulas de cortesía, como p. ej., 请 (qing, 'por favor'). Esta ausencia probablemente esté motivada por el hecho de que las peticiones se incluían en el seno de las conversaciones que mantenían los personajes, y rara vez ocurrían como inicio de estas como ocurre en los cuestionarios DCT.

22 Así los consideran, por ejemplo, Contreras y Zhao (2017). 


\begin{tabular}{|l|c|c|}
\cline { 2 - 3 } \multicolumn{1}{c|}{} & \multicolumn{2}{c|}{ Frecuencia } \\
\hline Tipología alertadores & $\mathrm{N}^{\mathrm{o}}$ & $\%$ \\
\hline Título o rol profesional del oyente & 10 & 6,37 \\
\hline Nombre de pila o apelativo amistoso del oyente & 19 & 12,10 \\
\hline Saludo & 0 & 0,00 \\
\hline Demostrativo & 2 & 1,27 \\
\hline Expresión de disculpa & 0 & 0,00 \\
\hline Expresión de cortesía & 0 & 0,00 \\
\hline Marcador interpersonal & 8 & 5,10 \\
\hline Combinación de varios de ellos (7+4) & 1 & 0,64 \\
\hline Total & 40 & 25,48 \\
\hline
\end{tabular}

Tabla 9: Tipología y frecuencia de alertadores en el acto de habla de la petición.

\section{CONCLUSIONES}

Es evidente que, además de la lengua, es relevante conocer el ethos cultural, cosmovisión y patrón interaccional de aquellos hablantes con los que, por diferentes motivos o fines, se establezcan relaciones comunicativas. Sin embargo, determinar o explicitar aquellos no es tarea simple, pues en muchas ocasiones esto ha llevado a esencializar ciertos comportamientos desde una perspectiva, además, eurocéntrica. Surgen, entonces, los estereotipos y prejuicios. Las investigaciones de carácter empírico, sobre muestras reales y con criterios objetivos de análisis pueden contribuir a realizar descripciones y explicaciones mucho más precisas y próximas a la realidad. Y es en este contexto en el que en este trabajo se propone el análisis e interpretación de las producciones lingüísticas y comportamientos comunicativos.

Contar con corpus conversacionales orales y espontáneos a disposición pública facilitaría y homogeneizaría el trabajo de los investigadores, y en consecuencia también la calidad de los resultados obtenidos en sus investigaciones. Mientras esto ocurre, el análisis de los productos culturales puede ser una opción metodológica adecuada para el fin propuesto, de hecho esta herramienta es la que se utiliza cuando se trata de reconstruir el habla real de otras épocas (Kádar, 2007). Tampoco es descartable la utilización de otros instrumentos metodológicos, como p. ej., DCT, si bien es cierto que la información que estos pueden aportar, aunque valiosa, es sustancialmente distinta a la que aportan los análisis de muestras reales.

Asimismo, el hecho de poder aplicar y contrastar constructos teóricos a lenguas tipológicamente distintas puede resultar revelador para mejorar la descripción de estos. Es por este motivo que a lo largo de este trabajo se ha realizado el análisis de un acto de habla, la petición, atendiendo a los supuestos teóricos y metodológicos propuestos por Blum-Kulka et alii (1989), Albelda (2007), Briz y Albelda (2013) y Briz (2017). El análisis de la muestra realizado ha evidenciado que la estrategia más habitual para realizar peticiones en la conversación oral en chino es la que se considera más directa o más 
impositiva; sin embargo, si solo se considerara este rasgo, se obviaría que dicha estrategia suele ir acompañada de recursos pragmáticos atenuadores, incluyendo en esta categoría las estrategias discursivas en forma de explicaciones o justificaciones de los actos de apoyo. No valorar estas cuestiones, así como tampoco otros factores contextuales y discursivos, dificulta la obtención de sólidas conclusiones que permitan la extrapolación o comparación interlingüística. En consecuencia, no se puede juzgar un patrón discursivo o comunicativo atendiendo únicamente a un aspecto lingüístico concreto y aislado.

\section{Referencias bibliográficas}

Albelda Marco, M. (2005). "Discordancia entre atenuación/cortesía e intensificación/descortesía en conversaciones coloquiales". En Blas, J. L. Casanova, M. y Velando, M. (eds.): Discurso y Sociedad. Contribuciones al estudio de la lengua en contexto social. Castellón: Universidad de Castellón, pp. 581-590.

Albelda Marco, M. (2007). La intensificación como categoría pragmática: revisión y propuesta. Frankfurt am Main: Peter Lang.

Albelda Marco, M. (2014). "Escalaridad y evaluación: rasgos caracterizadores de la intensificación pragmática”. En Putska, E. y Goldschmitt, S. (eds.), Emotionen, Expressivität Emphase. Berlín: Erich Schmidt Verlag, pp. 79-94.

Ballesteros, Martín, F. J. (2001). "La cortesía española frente a la cortesía inglesa. Estudio pragmalingüístico de las exhortaciones impositivas", Estudios Ingleses de la Universidad Complutense, 9, pp. 171- 207.

Blum-Kulka, S. House, J. y Kasper, G. (eds.) (1989). Cross-cultural pragmatics: Requests and apologies. Norwood (NJ): Ablex Publishing.

Bravo, D. (2005). "Categorías, tipologías y aplicaciones. Hacia una redefinición de la cortesía comunicativa”. En Bravo, D. (ed.), Estudios de la (des)cortesía en español. Categorías conceptuales y aplicaciones a corpora orales y escritos. Buenos Aires: Programa EDICE/Dunken, pp. 21-52.

Briz Gómez, A. (2012). "La (no)atenuación y la (des)cortesía, lo lingüístico y lo social, parejas, de hecho". En Escamilla Morales, J. y Henry Vega, G. (Eds.), Miradas multidisciplinares a los fenómenos de cortesía y descortesía en el mundo hispánico. Colombia: Universidad del AtlánticoPrograma EDICE, pp. 33-75.

Briz Gómez, A. (2017). "Una propuesta funcional para el análisis de la estrategia pragmática intensificadora en la conversación coloquial”. En Albelda, M. y Mihatsch, W. (Eds.), Atenuación e intensificación en géneros discursivos. Madrid: Iberoamericana, pp. 43-70.

Briz Gómez, A. y Albelda Marco, M. (2013). "Una propuesta teórica y metodológica para el análisis de la atenuación lingüística en español y portugués. La base de un proyecto en común (ES.POR. ATENUACIÓN)", Onomazein, 28, pp. 288 -319.

Briz, A., Pons, S. y Portolés, J. (coords.) (2008). Diccionario de partículas discursivas del español. www.dpde.es. (29-11-17)

Brown, P. y Levinson, S. (1987). Politeness: Some universals in language. Cambridge: Cambridge University Press. 13 ed.

Cestero Mancera, A. M. y Albelda Marco, M. (2012). "La atenuación lingüística como fenómeno variable", Oralia, 15, pp. 74-124.

Chao Yuen Ren (1968). A Grammar of Spoken Chinese. Berkeley: University of California Press.

Chen Chi Fen, E. (2001). Making E-Mail Requests to Professors: Taiwanese vs. American Students. http://www2.nkfust.edu.tw/ emchen/Home/Chen\%20Papers/Making\%20email\%20requests\%20 to\%20professors.pdf (29-11-17)

Coll Blackwell, A. (1997). "Recordando a Raymond R. Williams en el décimo aniversario de su muerte", Enrahonar, 28, pp. 33-53. 
Contreras, J. y Zhao Lishuang (2017). "Análisis contrastivo de estrategias de atenuación en un corpus de correos electrónicos españoles, alemanes y chinos". En Albelda, M. y Mihatsch, W. (eds.), Atenuación e intensificación en diferentes géneros discursivos. Madrid/Frankfurt: Iberoamericana /Veurvert, pp. 205-220.

Díaz Pérez, F. J. (2003). La Cortesía Verbal en Inglés y en Español: Actos de Habla y Pragmática Intercultural. Jaén: Universidad de Jaén.

Du Jinwen Steinberg (1995). "Performance of face-threatening acts in Chinese: Complaining, giving bad news, and disagreeing". En Kasper, G. (ed.), Pragmatics of Chinese as Native and Target Language. Honolulu: University of Hawaii Press, pp. 165-206.

Escandell-Vidal, M ${ }^{a}$ V. (1995). "Cortesía, fórmulas convencionales y estrategias indirectas", Revista Española de Lingüistica, 25, pp. 31-66.

Escandell-Vidal, M ${ }^{\mathrm{a}}$ V. (2004). "Aportaciones de la Pragmática”. En Sánchez Lobato, J. y Santos Gargallo, I (dirs.), Enseñar español como segunda lengua o lengua extranjera. Vademécum para la formación de profesores. Madrid: SGEL, pp. 179-198.

Gao Ge y Ting-Toomey, S. (1998). Communicating Effectively With The Chinese. Thousand Oaks: Sage Publications.

Hang Yang (1988). A pragmatic study of some sentence-final and post-verbal particles in Mandarin Chinese. Tesis doctoral. University of York. http://etheses.whiterose.ac.uk/id/eprint/4278 (29-11-17)

Haverkate, H. (1994). La Cortesía Verbal: Estudio Pragmalingüístico. Madrid: Gredos.

Kádár, D. Z. (2007). "On historical Chinese apology and its strategic application”, Journal of politeness Research, 3, pp. 125-150.

Kirpatrick, A. (1991). "Information sequencing in Mandarin in letters of request", Anthropological Linguistics, 33(2), pp.1-20.

Kirpatrick, A. (1995). "Chinese rhetoric: Methods of argument”, Multilingua, 14-3, pp.271-295.

Lee-Wong Song Mei (1994). "Imperatives in requests: Direct or impolite-observations from Chinese", Pragmatics, 4(4), pp. 491-515.

Lee-Wong Song Mei (1998). "Face support-Chinese particles as mitigators: A study of BA A/YA and NE", Pragmatics, 8, pp. 387-404.

Lee-Wong Song Mei (2000). Politeness and Face in Chinese Culture. Frankfurt am Main: Peter Lang.

Li Xinghua (2016). Aspectos contrastivos de los actos de habla de petición en chino y en español. UVA: Tesis doctoral http://uvadoc.uva.es/handle/10324/18815 (29-11-17)

Li Wei (2015). "A Sociopragmatic Analysis of Email Requests in Mandarin Chinese and Australian English". En Ko, Leond y Chen Ping (eds.), Translation and Cross-Cultural Communication Studies in the Asia Pacific. Netherlands: Brill, pp. 437-457.

Li, C. y Thompson, S. (1989). Mandarin Chinese: A functional reference grammar. California: Univ of California Press.

Ma, R. (1996). "Saying “yes" for "no" and "no" for "yes": Chinese rule", Journal of Pragmatics, 25, pp. 257-266.

Padilla Foster, M ${ }^{\mathrm{a}}$ M. (2016). La comunicación intercultural: pragmática de la petición en español y en chino mandarín. UCM. Tesis doctoral http://eprints.ucm.es/38123/ (29-11-17)

Pan Yuling (2000). Politeness in Chinese Face to Face Interaction. Amsterdam: Elsevier.

Placencia, Ma . E. (2010). “(Des)cortesía, migración y comunicación”. En Orletti, F. y Mariottini, L. (eds.), (Des)cortesía en español. Espacios teóricos y metodológicos para su estudio. Estocolmo: Edice, pp. 399-429.

Querol Bataller, M. (2016). "Estrategias, alertadores y actos de apoyo en las peticiones en chino y español: esbozo de una comparación”, Pragmalingüística, no 24 , pp. 208-229.

Querol Bataller, M. (en prensa). “吧 (ba) vs. 啊 (a), atenuación e intensificación en la conversación en chino", Pragmalingüística, ${ }^{\circ} 28$.

Rue Yong-Ju y Zhang Grace Qiao (2008). Request strategies: A comparative study in Mandarin Chinese and Korean. Amsterdam: John Benjamins Publishing. 
Schneider, S. (2017). "Las dimensiones de la intensificación y de la atenuación”. En Albelda, M. y Mihatsch, W. (eds.), Atenuación e intensificación en diferentes géneros discursivos (pp. 23-42). Madrid/Frankfurt: Iberoamericana /Veurvert.

Siebold, K. (2008). Actos de habla y cortesía verbal en español y en alemán. Estudio pragmalingüistico e intercultural. Frankfurt: Peter Lang.

Spencer-Oatey, H. (2008). Culturally Speaking. Culture, Communication and Politeness Theory. London: Continuum, 2. ${ }^{\mathrm{a}} \mathrm{ed}$.

Tsuzuki, M.; Takahashi, K.; Patschke, C. Y Zhang, Q. (2005). "Selection of linguistic forms for requests and offers: Comparison between English and Chinese". En Lakoff, R. T., y Ide, S. (eds.), Broadening the horizon of linguistic politeness. Amsterdam: John Benjamins Publishing, pp. 283-298.

Wang Shengli (2011). "Request Strategies in Contemporary Chinese Teledramas- A Corpus-based Study", Theory and Practice in Language Studies, vol. 1, nº, pp. 1139-1149.

Wang Ying Xian (2013): On Chinese Modal Particle A (啊). A Pragmatic and Semantic Study. Bern: Peter Lang.

Zhang Yanyin (1995a): "Strategies in Chinese requesting”. En Kasper, G. (ed.), Pragmatics of Chinese as Native and target Languages. Honolulu: University of Hawaii, pp. 23-68. 
